\title{
Age-dependent changes of p53 and p63 immunoreactivities in the mouse hippocampus
}

\author{
Tae-Kyeong Lee ${ }^{1 \dagger}$, Young Eun Park ${ }^{1 \dagger}$, Cheol Woo Park' ${ }^{1}$ Bora Kim', Jae-Chul Lee ${ }^{1}$, Joon Ha Park ${ }^{2}$, Hyang-Ah Lee ${ }^{3}$, \\ Moo-Ho Won ${ }^{1 *}$ (D) and Ji Hyeon Ahn ${ }^{4^{*}}$
}

\begin{abstract}
P53 and its family member p63 play important roles in cellular senescence and organismal aging. In this study, p53 and p63 immunoreactivity were examined in the hippocampus of young, adult and aged mice by using immunohistochemistry. In addition, neuronal distribution and degeneration was examined by NeuN immunohistochemistry and fluoro-Jade B fluorescence staining. Strong p53 immunoreactivity was mainly expressed in pyramidal and granule cells of the hippocampus in young mice. p53 immunoreactivity in the pyramidal and granule cells was significantly reduced in the adult mice. In the aged mice, p53 immunoreactivity in the pyramidal and granule cells was more significantly decreased. p63 immunoreactivity was strong in the pyramidal and granule cells in the young mice. p63 immunoreactivity in these cells was apparently and gradually decreased with age, showing that p63 immunoreactivity in the aged granule cells was hardly shown. However, numbers of pyramidal neurons and granule cells were not significantly decreased in the aged mice with normal aging. Taken together, this study indicates that there are no degenerative neurons in the hippocampus during normal aging, showing that p53 and p63 immunoreactivity in hippocampal neurons was progressively reduced during normal aging, which might be closely related to the normal aging processes.
\end{abstract}

Keywords: Aging process, Granule cells, Mouse, Hippocampus, p53, p63, Pyramidal neurons

\section{Introduction}

The p53 gene family is composed of a group of transcription factors including a key tumor suppressor $\mathrm{p} 53$, and its homologs p63 and p73 [1, 2]. It has widely been reported that the majority of human cancers show mutations that abrogate p53 network which is related to many antiproliferative cellular responses in context-dependent manner [3-5]. In rodent and human brains, p53 and p63 expressions have been reported. p53 mRNA is expressed in the mouse [6] and rat [7] brain, and p63 mRNA and proteins are expressed in the human hippocampus and cortex [8]. Recently, researches on the activity of p53 or

\footnotetext{
* Correspondence: mhwon@kangwon.ac.kr; jh-ahn@hallym.ac.kr

Tae-Kyeong Lee and Young Eun Park are Co-first author.

'Department of Neurobiology, School of Medicine, Kangwon National University, Chuncheon, Gangwon 24341, Republic of Korea

${ }^{4}$ Department of Biomedical Science, Research Institute of Bioscience and Biotechnology, Hallym University, Chuncheon, Gangwon 24252, Republic of Korea

Full list of author information is available at the end of the article
}

p63 in noncancer (normal) tissues in response to cerebral ischemia have been examined [9-11].

Aging is defined as progressive decline of normal body functions necessary for survival and reproduction accompanied by accumulation of deleterious changes (molecular and cellular damages) that result in increased risk of diseases and death [12]. The loss of maintenance of DNA integrity contributes to the onset of cellular senescence or cell death, and this genomic instability is caused by oxidative stress, genotoxic drugs and replication errors [2].

Emerging evidence has suggested that p53 family members exert powerful roles in maintaining genome stability by halting cell proliferation, and they are functionally involved in DNA damage response including cell cycle arrest and apoptosis by controlling DNA repair protein expression, which ultimately regulates cellular senescence and aging process $[2,3,13]$. In addition, these different responses of cells such as cell cycle arrest, 
apoptosis, or senescence have been reported to be dependent on cell type or the level of p53 when numerous p53 target genes are upregulated in many biological processes [5].

So far, a number of studies have been reported on p53mediated senescence. Most of the studies have focused on the role of senescence program and p53 action associated with a permanent cell cycle arrest as a tumor suppressor mechanism, while some of the studies have reported the protective role of senescence and p53 action (in limiting liver fibrosis) which is related to noncancer pathology [5, 14, 15]. In addition, little is known about age-dependent change of p53 and p63 expressions in the mouse hippocampus during the normal aging. Therefore, we investigated age-related changes in p53 and p63 immunoreactivities in the hippocampus of young, adult and aged mice, as a useful model for age research $[16,17]$.

\section{Materials and methods}

\section{Experimental animals}

Male ICR mice were purchased from Orient Bio Inc. (Seongnam, South Korea) and used at postnatal month (PM) 1, PM 6 and PM 24 as young, adult and aged group, respectively, according to the definition of the life history phases of mice [18]. Mice ( $n=7$ in each group) were housed and provided free access to food and water in a conventional state under adequate temperature (about $23^{\circ} \mathrm{C}$ ) and humidity (about $60 \%$ ) control with a 12-h light/12-h dark cycle. For animal handling and care, we complied with the guidelines of current international laws and policies (NIH Guide for the Care and Use of Laboratory Animals, The National Academies Press, 8th Ed., 2011). In addition, our experimental protocol was approved (approval no. KW-180124-2) by Institutional Animal Care and Use Committee of Kangwon National University (Chuncheon, Republic of Korea).

\section{Tissue processing for histology}

All mice were anesthetized by a single intraperitoneal injection of $60 \mathrm{mg} / \mathrm{kg}$ pentobarbital sodium (JW Pharm. Co., Ltd., Republic of Korea). They were transcardially rinsed with 0.1 M phosphate-buffered saline (PBS, pH 7.4) (Sigma, St. Louis, MO, USA) and fixed with $4 \%$ paraformaldehyde (Sigma, St. Louis, MO, USA) in 0.1 M PBS (pH 7.4) (Sigma, St. Louis, MO, USA). Their brains were removed and postfixed with the same fixative for $5 \mathrm{~h}$, and the brain tissues were cryoprotected by infiltration with $30 \%$ sucrose (Sigma, St. Louis, MO, USA) for $8 \mathrm{~h}$. The brain tissues were then frozen and transversely sectioned into 30- $\mu \mathrm{m}$ thickness in a cryostat (CM1520, Leica Microsystems, Wetzlar, Germany).

\section{Immunohistochemistry}

To examine age-related change in p53, p63 and NeuN (a marker for neurons) immunoreactivity in the mouse hippocampus, immunohistochemical stainings and their quantitative analyses were performed according to our published method [11]. We used polyclonal rabbit antip53 antibody (cat. no. ab131442, 1:250; Abcam, Cambridge, MA, USA), polyclonal rabbit anti-p63 antibody (cat. no. ab53039, 1:250; Abcam, Cambridge, MA, USA), and polyclonal mouse anti-NeuN (cat. no. MAB377, 1: 200; Millipore, Cambridge, MA, USA) as primary antibodies. According to our method, the brain sections were reacted with each antibody at $4{ }^{\circ} \mathrm{C}$ for $8 \mathrm{~h}$ and followed by biotinylated goat anti-rabbit IgG or horse anti-mouse (1:200; Vector Laboratories, Burlingame, CA, USA) and streptavidin peroxidase complex (1:200; Vector Laboratories, Burlingame, CA, USA) at room temperature for $2 \mathrm{~h}$. Each negative control test was carried out by using pre-immune serum (Vector Laboratories, Burlingame, CA, USA) instead of each primary antibody to establish the specificity of each immunostaining. All negative control tests showed no immunoreactivity in any cells.

According to anatomical landmarks of the mouse brain atlas, we selected seven sections with $120-\mu \mathrm{m}$ intervals per animal and quantitatively analyzed p53, p63 and NeuN immunoreactivity, respectively. As previously described [11], we captured the digital image of each immunoreactivity in the mouse hippocampus under an AxioM1 light microscope (Carl Zeiss, Germany) equipped with a digital camera (Axiocam, Carl Zeiss, Germany) connected to a PC monitor.

P53 and p63 immunoreactive structures were captured in a $250 \times 250 \mu \mathrm{m}$ square in the hippocampus and analyzed by relative immunoreactivity with an image analyzing system (software: Optimas 6.5, CyberMetrics, Scottsdale, AZ). The immunoreactivity of p53 and p63 was evaluated by optical density (OD). OD was obtained after the transformation of the mean gray level by using a formula: $\mathrm{OD}=\log (256 /$ mean gray level). The background density was subtracted, and a ratio of OD was calibrated as \% (relative OD, ROD) by using Adobe Photoshop (version 8.0). Finally, ROD was evaluated by using Image J 1.46 software (National Institutes of Health, Bethesda, MD, USA). A ratio of ROD was calibrated as \%, with the young group (100\%).

To evaluate neuronal distribution in the hippocampus, NeuN immunoreactive neurons were counted in a $250 \times$ $250 \mu \mathrm{m}$ square in the hippocampus with an image analyzing system (software: Optimas 6.5, CyberMetrics, Scottsdale, AZ). Cell counts were obtained by averaging all counts obtained from each animal.

\section{Fluoro-jade B (F-J B) histofluorescence staining}

To examine whether hippocampal neurons are intact or not in each group, F-J B (a fluorescent marker for cellular degeneration) histofluorescence staining was done as described previously [19]. Briefly, the brain sections were 
immersed in a $1 \%$ solution of sodium hydroxide (SigmaAldrich, MO, USA) for $5 \mathrm{~min}$, transferred to a solution of $0.06 \%$ potassium permanganate (Sigma-Aldrich, MO, USA) for $20 \mathrm{~min}$ and incubated in a solution of $0004 \% \mathrm{~F}-\mathrm{J}$ B (Histochem, Jefferson, AR, USA) for 45 min. Finally, the reacted sections were washed and placed on a slide warmer (approximately $50^{\circ} \mathrm{C}$ ) for the reaction. Images of F-J B positive cells were captured with an AxioM1 light microscope (Carl Zeiss, Göttingen, Germany) equipped with a digital camera (Axiocam, Carl Zeiss, Germany) connected to a PC monitor.

\section{Statistical analysis}

The data shown here represent the means \pm SEM. Differences of the means among the groups were statistically analyzed by analysis of variance (ANOVA) with a post hoc Bonferroni's multiple comparison test in order to elucidate age-related differences among groups. Statistical significance was considered at $P<0.05$.

\section{Results}

In this study, we examined p53, p63 and NeuN immunoreactivity, and F-J B histofluorescence in the hippocampus proper, which consists of Cornu Ammonis 1-3 subfields (CA1-3), and in the dentate gyrus.

\section{p53 immunoreactivity}

CA1-3

In the young group, strong p53 immunoreactivity was detected in pyramidal cells, which consist of the stratum pyramidale, and in non-pyramidal cells, which are located in the stratum oriens and radiatum (Fig. $1 \mathrm{~A}, \mathrm{D}, \mathrm{G})$. In the adult group, p53 immunoreactivity in the pyramidal cells was significantly decreased $(52.4 \%$ in the CA1 and $55.6 \%$ in the CA2/3 of the young) (Fig. $1 \mathrm{~B}, \mathrm{E}, \mathrm{H}, \mathrm{M}$ ). In the aged group, p53 immunoreactivity in the pyramidal cells was more decreased (14.6\% in the CA1 and $16.1 \%$ in the CA2/ 3 of the young and $27.8 \%$ in the CA1 and $18.7 \%$ in the CA2/3 of the adult) (Fig. 1 C, F, I, M).

\section{Dentate gyrus}

Strong p53 immunoreactivity was easily shown in granule cells, which consist of the granule cell layer, and in hilar cells, which are located in the polymorphic layer (Fig. $1 \mathrm{~J}$ ). p53 immunoreactivity in the granule cells was significantly and gradually decreased with age. The ROD in the adult and aged was 46.1 and $18.7 \%$, respectively, of the young (Fig. $1 \mathrm{~K}, \mathrm{~L}, \mathrm{M}$ ).

\section{p63 immunoreactivity}

\section{CA1-3}

In the young group, strong p63 immunoreactivity was found in pyramidal of the stratum pyramidale (Fig. 2 A, D, G). In the adult group, p63 immunoreactivity in the pyramidal cells was significantly decreased $(39.1 \%$ in the CA1 and $63.5 \%$ in the CA2/3 of the young) compared to that in the young group (Fig. $1 \mathrm{~B}, \mathrm{E}, \mathrm{H}, \mathrm{M}$ ). Furthermore, p63 immunoreactivity in the pyramidal cells of the aged group was more decreased $(9.1 \%$ in the CA1 and $34.1 \%$ in the CA2/3 of the young and $23.1 \%$ in the CA1 and $53.7 \%$ in the CA2/3 of the adult) (Fig. 2 C, F, I, M).

\section{Dentate gyrus}

In the young group, p63 immunoreactivity in the dentate gyrus was weakly shown in granule cells, and relatively strong p63 immunoreactivity was detected in hilar cells (Fig. 2 J). In the adult group, p63 immunoreactivity was significantly decreased in the granule cells, showing that the ROD of p63 immunoreactivity of the adult was $47.6 \%$ of the young (Fig. $2 \mathrm{~K}, \mathrm{M}$ ). In the aged group, p63 immunoreactivity in granule cells was very low, showing that the ROD of p63 immunoreactivity in the aged dentate gyrus was $11.6 \%$ of the young (Fig. 2 L, M).

\section{NeuN immunoreactivity}

In the young group, NeuN immunoreactive cells were mainly detected in the stratum pyramidale of the hippocampus proper (CA1-3) (Fig. $3 \mathrm{~A}, \mathrm{D})$ and in the granule cell layer and polymorphic layer of the dentate gyrus (Fig. $3 \mathrm{G}$ ). In the adult and aged groups, the distribution pattern of NeuN immunoreactive cells was similar to that in the young group, showing that the mean number of NeuN immunoreactive cells in the stratum pyramidale and in the granule cell layer was not significantly different from that the young group (Fig. 3 B, C, E, F, H, I, J).

\section{F-J B immunofluorescence}

F-J B positive cells were not detected in any layers in the CA1-3 (Fig. 3 a-f) and the dentate gyrus (Fig. 3 g-i) in all groups.

\section{Discussion}

In the present study, we found that each p53 and p63 immunoreactivity was mainly expressed in pyramidal and granule cells in the young, adult and aged mouse hippocampus. This finding is consistent with previous studies. Ding et al. (2014) have reported that specific p53 expression is shown in hippocampal pyramidal cells of young adult (6-8 weeks of age) [20] and aged (20-29 months of age) [7] rats. In addition, Napieralski et al. (1999) have reported that p53 mRNA is detected in pyramidal cells of the CA1-CA3 subregions and granule cells of the dentate gyrus of the adult rat [21]. In regard to p63 expression, we have reported that p63 immunoreactivity is shown in hippocampal pyramidal cells of young and adult gerbils [11, 22]. In addition, Hernandez-Acosta et al. (2011) have reported that, in the young mouse hippocampus, strong p63 immunoreactivity is found in pyramidal cells of the 


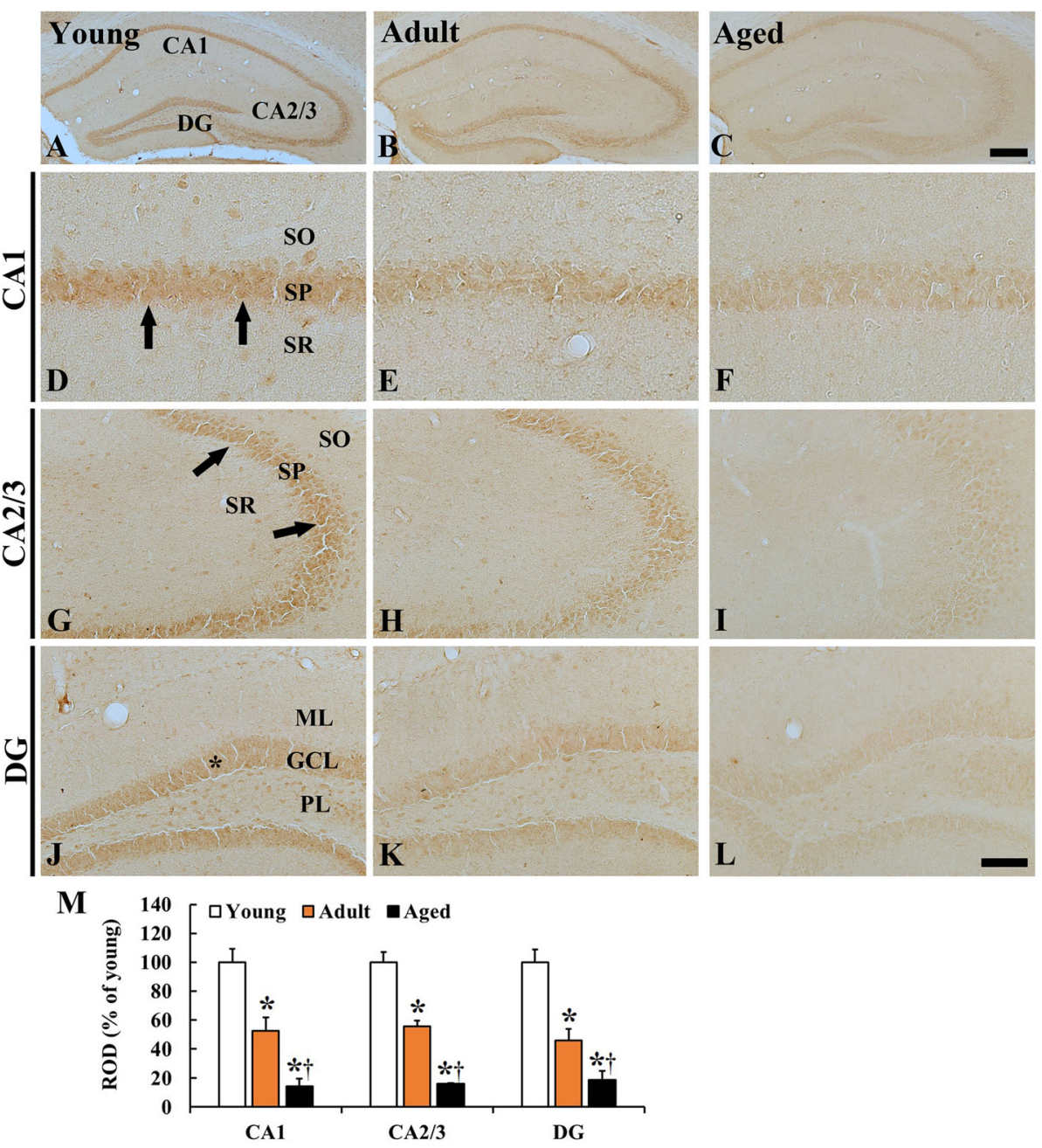

Fig. 1 a-l p53 immunohistochemistry in the hippocampus of the young $(\mathbf{a}, \mathbf{d}, \mathbf{g}, \mathbf{j})$, adult $(\mathbf{b}, \mathbf{e}, \mathbf{h}, \mathbf{k})$ and aged $(\mathbf{c}, \mathbf{f}, \mathbf{i}, \mathbf{I})$ mice. p53 immunoreactivity is shown in the pyramidal cells (arrows) and granule cells (asterisk) in the young mouse hippocampus. p53 immunoreactivity in these cells is significantly and gradually decreased during aging process. GCL, granule cell layer; $\mathrm{ML}$, molecular layer; PL, polymorphic layer; $\mathrm{SO}$, stratum oriens; SP, stratum pyramidale; SR, stratum radiatum. Scale bar $=400 \mu \mathrm{m}$ (A-C) and $100 \mu \mathrm{m}$ (D-L). (M) ROD as \% of p53 immunoreactive cells in the hippocampus ( $n=7$ per group; ${ }^{*} P<0.05$, significantly different from the young group, ${ }^{\dagger} P<0.05$, significantly different from the adult group). The bars indicate the means \pm SEM

hippocampus proper (CA1-3) and hilar cells of the dentate gyrus, showing that p63 immunoreactivity in dentate granule cells is relatively weak [8]. This finding is consistent with our present study on the young mouse. Based on previous and our current studies, we insist that p53 and p63 immunoreactivity in rodent hippocampi is typically expressed in pyramidal and granule cells in the rodent hippocampus.

In our current study, p53 and p63 immunoreactivity in the mouse hippocampus was highest at young. It has been reported that p53 serves to ameliorate the disruption of neuronal development after irradiation by inhibiting neural progenitor activation in the young (10 weeks old) mouse dentate gyrus [23]. Furthermore, Hernandez-Acosta et al. (2011) have reported that p63 protein level in the young adult mouse brain is significantly higher than that at embryonic and early postnatal stage, and they suggested that p63 gene might play more important roles in neuronal maintenance in adulthood than neuronal development at early postnatal stage [8]. In addition, it has been demonstrated that p63 is essential for the development and maintenance of stratified epithelial tissues [24, 25]. Based on the results of previous and our current studies, it is postulated that strong p53 and p63 expressions in pyramidal and granule cells in the young hippocampus is related to neuronal maintenance in the hippocampus in young period.

We, in this study, found that p53 and p63 immunoreactivity in the mouse hippocampus was dramatically decreased in the aged group compared to that in the 


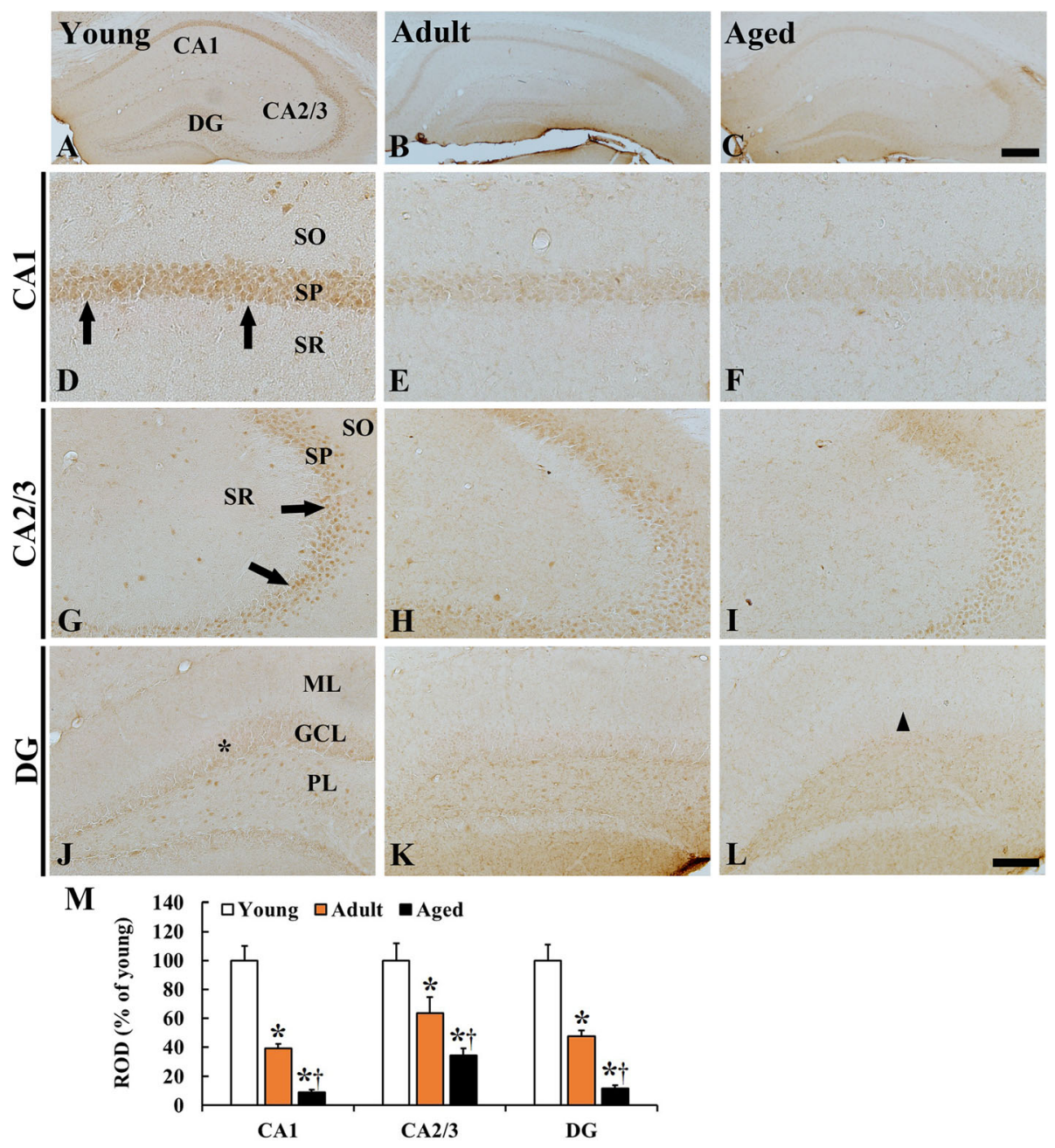

Fig. 2 A-L p63 immunohistochemistry in the hippocampus of the young $(\mathbf{a}, \mathbf{d}, \mathbf{g}, \mathbf{j})$, adult $(\mathbf{b}, \mathbf{e}, \mathbf{h}, \mathbf{k})$ and aged $(\mathbf{c}, \mathbf{f}, \mathbf{i}, \mathbf{I})$ mice. p63 immunoreactivity is found in pyramidal cells (arrows) and granule cells (asterisk) in the young mouse hippocampus. p63 immunoreactivity is gradually reduced during aging, showing that p63 immunoreactivity is hardly shown in aged granule cells (arrowhead). GCL, granule cell layer; ML, molecular layer; PL, polymorphic layer; SO, stratum oriens; SP, stratum pyramidale; SR, stratum radiatum. Scale bar $=400 \mu \mathrm{m}(\mathbf{A}-\mathbf{C}$ and a-c) and $100 \mu \mathrm{m}$ (D-L and d-I). (M) Relative optical density (ROD) as \% of p63 immunoreactive cells in the hippocampus $\left(n=7\right.$ per group; ${ }^{*} P<0.05$, significantly different from the young group, ${ }^{\dagger} P<0.05$, significantly different from the adult group). The bars indicate the means \pm SEM

young and adult groups. This is in accordance with previous studies that show that aging is enhanced when $\mathrm{p} 53$ or p63 is removed by genetic modification. Namely, Moore et al. (2007) have demonstrated that truncated form of p53 protein increases wild-type p53 activity and promotes the aging process, which reduces life span [26]. Armata et al. (2007) have reported that, in p53 $3^{\mathrm{S} 18 \mathrm{~A}}$ mice, Serine ${ }^{18}$ of p53 is replaced with non-phosphorylable alanine and displays signs of accelerated aging [27]. Some researchers have reported that $\mathrm{p} 63^{+/-}$mice show a decreased lifespan and features of accelerated aging with decreased proliferation and enhances expressions of senescent markers such as senescence-associated- $\beta$-galactosidase, promyelocytic leukemia protein, and tumor suppressors $\mathrm{p} 16^{\mathrm{INK} 4 \mathrm{a}}$, suggesting that $\mathrm{p} 63$ deficiency causes cellular senescence and organismal aging [13, 28]. Furthermore, Keyes et al. (2005) have demonstrated that p53 depletion prevents aging induced by loss of p63 in vitro, indicating that interaction between p53-related proteins functionally regulate the aging process [28]. Therefore, it is postulated that one of physiological p53 and p63 activities may be involved in protecting tissues from aging-associated characters and that predominantly decreased p53 and p63 immunoreactivity in the aged hippocampus may be closely related to one of features of normal aging process.

p53 and its family member p63 are important regulators in aging, and p53 can prevent or promote aging in a context-dependent manner [2, 3, 13]. Mechanisms to regulate aging and longevity by p53 include regulation of 


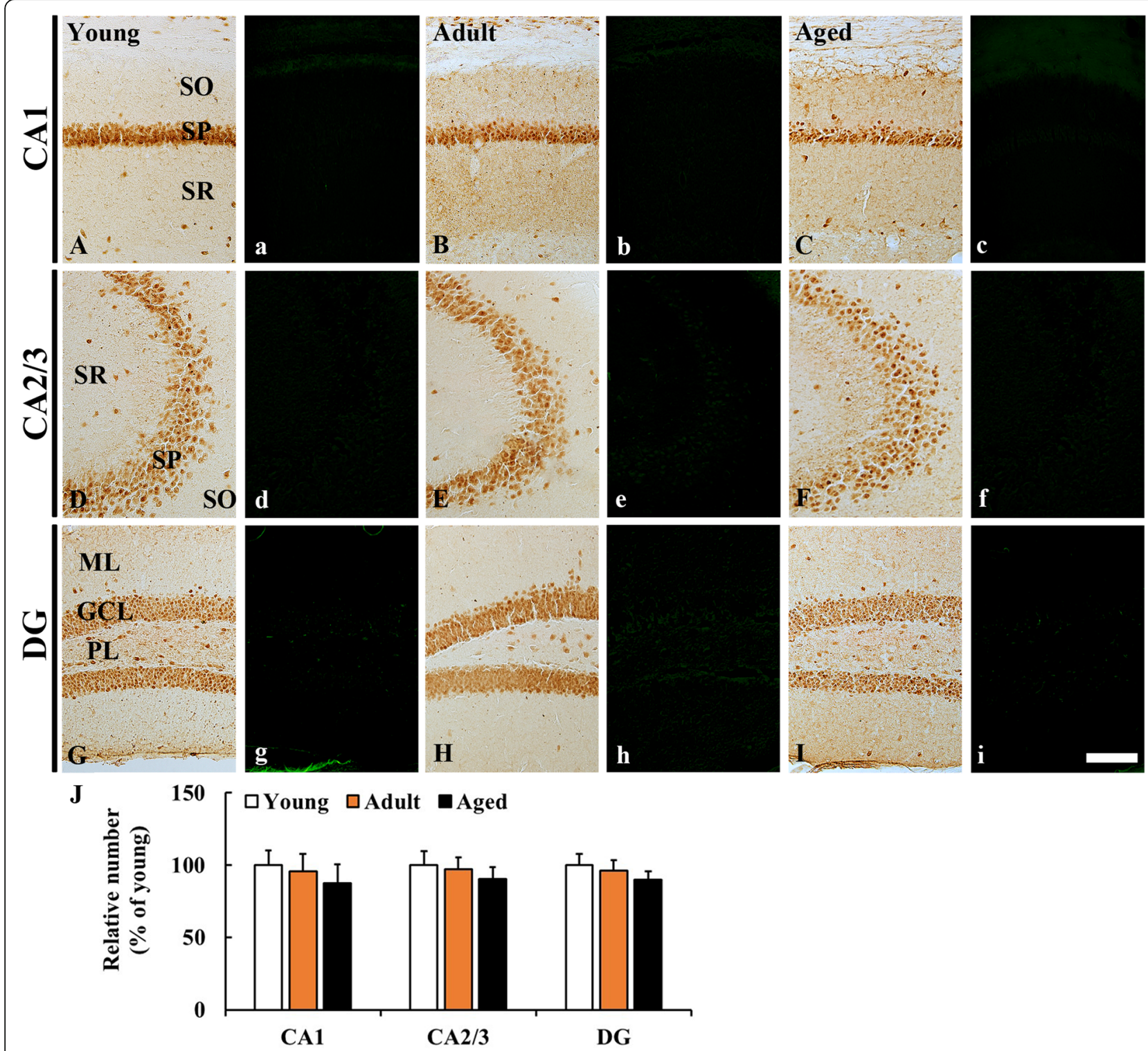

Fig. 3 A-I, a-i NeuN immunohistochemistry (A-I) and F-J B fluorescence staining (a-i) in the hippocampus of the young (A, D, G, a, d, $\mathbf{g})$, adult $(\mathbf{B}, \mathbf{E}, \mathbf{H}, \mathbf{b}, \mathbf{e}, \mathbf{h})$, and aged $(\mathbf{C}, \mathbf{F}, \mathbf{l}, \mathbf{C}, \mathbf{f}, \mathbf{i})$ mice. In all groups, NeuN immunoreactive neurons are mainly found in the stratum pyramidale (SP) and granule cell layer (GCL), and numbers of NeuN immunoreactive neurons is not significantly different among all the groups. In addition, No F-J B positive cells are detected in any groups. Scale bar $=100 \mu \mathrm{m}$. (j) The mean number of NeuN immunoreactive neurons in the hippocampus $(n=7$ per group). The bars indicate the means \pm SEM

mammalian target of rapamycin (mTOR) signaling and reactive oxygen species (ROS) generation as follows. Under no or low stress condition, p53 can reduce mTOR signaling and decrease ROS by inducing antioxidant genes expression, whereas, under severe stress, active p53 increases intracellular ROS, which leads to pro-apoptotic and pro-senescent activities [3, 29]. Indeed, in our current study, we have not found agerelated neuronal death/degeneration of pyramidal and granule cells in the aged mouse hippocampus with a marked reduction in p53 and p63 immunoreactivity. In addition, it has been investigated that mTOR phosphorylation is significantly decreased in the hippocampus of aged mice [30] and aged gerbils [31], and that some antioxidant, such as $\mathrm{Cu} / \mathrm{Zn}$ SOD immunoreactivity is gradually increased in the hippocampal CA1 with age (from 5 to 15 months of age) in mice [32], although other antioxidant catalase immunoreactivity is decreased in the mouse hippocampus during aging [33]. On the other hand, it has been reported that significant loss of Purkinje cells in the aged rat cerebellum is closely related to upregulation of p53 in the Purkinje cells [7]. Taken 
together, significantly reduced p53 and p63 expression in senescent mouse hippocampus likely that normal aging is not a severe stress situation, which is closely related to absence of neuronal cell death.

\section{Conclusion}

Our current study showed that p53 and p63 immunoreactivity in the mouse hippocampus during the normal aging process was gradually and significantly reduced in an age-dependent manner, showing no death or loss of any pyramidal cells in aged mice. These findings suggest that decrease in p53 and p63 expression may be closely related to age-associated changes in the hippocampus, and it can be clinically used as indicators of normal or abnormal aging.

\section{Abbreviations}

CA: Cornu ammonis; F-JB: Fluoro Jade B; mTOR: Mammalian target of rapamycin; OD: Optical density; ROD: Relative optical density; ROS: Reactive oxygen species

\section{Acknowledgements}

The authors would like to thank Mr. Seung Uk Lee and Ms. Hyun Sook Kim for their technical help in this study.

\section{Authors' contributions}

$\mathrm{CP}$ and BK performed the measurements, YP, JL, HL, and JP analyzed and interpreted data, and TL, MW and JA made substantial contributions to conception and design, and were involved in drafting, revising the manuscript and interpreting all data. All Authors read and approved the final manuscript.

\section{Funding}

This work was carried out with the support of "Cooperative Research Program for Agriculture Science and Technology Development (Project No. PJ01329401)" Rural Development Administration.

\section{Availability of data and materials}

All data generated or analyzed during this study are included in this published article.

\section{Ethics approval and consent to participate}

Experimental procedure for this study was approved by the Institutional Animal Care and Use Committee at Kangwon National University (approval number: KW-180124-2).

\section{Consent for publication}

Not applicable.

\section{Competing interests}

The authors have no financial competing interest.

\section{Author details}

${ }^{1}$ Department of Neurobiology, School of Medicine, Kangwon National University, Chuncheon, Gangwon 24341, Republic of Korea. ${ }^{2}$ Department of Anatomy, College of Korean Medicine, Dongguk University, Gyeongju, Gyeongbuk 38066, Republic of Korea. ${ }^{3}$ Department of Obstetrics and Gynecology, School of Medicine, Kangwon National University, Chuncheon, Gangwon 24341, Republic of Korea. ${ }^{4}$ Department of Biomedical Science, Research Institute of Bioscience and Biotechnology, Hallym University, Chuncheon, Gangwon 24252, Republic of Korea.
Received: 7 August 2019 Accepted: 9 October 2019

Published online: 29 October 2019

\section{References}

1. Mendrysa SM, Ghassemifar S, Malek R. p53 in the CNS: perspectives on development, stem cells, and Cancer. Genes Cancer. 2011;2:431-42.

2. Nicolai S, Rossi A, Di Daniele N, Melino G, Annicchiarico-Petruzzelli M, Raschella G. DNA repair and aging: the impact of the p53 family. Aging (Albany NY). 2015;7:1050-65.

3. Feng $Z$, Lin M, Wu R. The regulation of aging and longevity: a new and complex role of p53. Genes Cancer. 2011;2:443-52.

4. Murray-Zmijewski F, Lane DP, Bourdon JC. p53/p63/p73 isoforms: an orchestra of isoforms to harmonise cell differentiation and response to stress. Cell Death Differ. 2006;13:962-72.

5. Zilfou JT, Lowe SW. Tumor suppressive functions of p53. Cold Spring Harb Perspect Biol. 2009;1:a001883.

6. Tohidi F, Toosi M, Azimian H, Khademi S, Fardid R, Sarab GA. The gene expression level of p53 and p21 in mouse brain exposed to radiofrequency field. Int J Radiat Res. 2015;13:337-43.

7. Chung YH, Shin C, Kim MJ, Lee B, Park KH, Cha Cl. Immunocytochemical study on the distribution of p53 in the hippocampus and cerebellum of the aged rat. Brain Res. 2000:885:137-41.

8. Hernandez-Acosta NC, Cabrera-Socorro A, Morlans MP, et al. Dynamic expression of the p53 family members p63 and p73 in the mouse and human telencephalon during development and in adulthood. Brain Res. 2011:1372:29-40.

9. Tounai H, Hayakawa N, Kato H, Araki T. Immunohistochemical study on distribution of NF-kappaB and p53 in gerbil hippocampus after transient cerebral ischemia: effect of pitavastatin. Metab Brain Dis. 2007;22:89-104.

10. Yonekura I, Takai K, Asai A, Kawahara N, Kirino T. p53 potentiates hippocampal neuronal death caused by global ischemia. J Cereb Blood Flow Metab. 2006;26:1332-40.

11. Lee JC, Cho GS, Kim IH, et al. p63 expression in the gerbil Hippocampus following transient ischemia and effect of ischemic preconditioning on p63 expression in the ischemic Hippocampus. Neurochem Res. 2015;40:1013-22.

12. Tosato M, Zamboni V, Ferrini A, Cesari M. The aging process and potential interventions to extend life expectancy. Clin Interv Aging. 2007;2:401-12.

13. Keyes WM, Mills AA. p63: a new link between senescence and aging. Cell Cycle. 2006;5:260-5.

14. Campisi J, D'Adda di Fagagna F. Cellular senescence: when bad things happen to good cells. Nat Rev Mol Cell Biol. 2007:8:729-40.

15. Krizhanovsky V, Yon M, Dickins RA, et al. Senescence of activated stellate cells limits liver fibrosis. Cell. 2008;134:657-67.

16. Mitchell SJ, Scheibye-Knudsen M, Longo DL, de Cabo R. Animal models of aging research: implications for human aging and age-related diseases. Annu Rev Anim Biosci. 2015;3:283-303.

17. Vanhooren $V$, Libert $C$. The mouse as a model organism in aging research: usefulness, pitfalls and possibilities. Ageing Res Rev. 2013;12:8-21.

18. Flurkey K, Currer JM, Harrison DE. The Mouse in Aging Research. In: Fox JG, et al., editors. In The Mouse in Biomedical Research. 2nd ed. Burlington: American College Laboratory Animal Medicine (Elsevier); 2007. p. 637-72.

19. Ahn JH, Ohk TG, Kim DW, et al. Fluoro-jade B histofluorescence staining detects dentate granule cell death after repeated five-minute transient global cerebral ischemia. Metab Brain Dis. 2019;34:951-6.

20. Ding DX, Tian FF, Guo JL, et al. Dynamic expression patterns of ATF3 and p53 in the hippocampus of a pentylenetetrazole-induced kindling model. Mol Med Rep. 2014;10:645-51.

21. Napieralski JA, Raghupathi R, Mclntosh TK. The tumor-suppressor gene, p53, is induced in injured brain regions following experimental traumatic brain injury. Mol Brain Res. 1999;71:78-86.

22. Bae EJ, Chen BH, Yan BC, et al. Delayed hippocampal neuronal death in young gerbil following transient global cerebral ischemia is related to higher and longer-term expression of p63 in the ischemic hippocampus. Neural Regen Res. 2015;10:944-50.

23. Li YQ, Cheng ZC, Liu SW, Aubert I, Wong CS. P53 regulates disruption of neuronal development in the adult hippocampus after irradiation. Cell Death Dis. 2016:2:16072.

24. Mills AA, Zheng B, Wang X-J, Vogel H, Roop DR, Bradley A. p63 is a p53 homologue required for limb and epidermal morphogenesis. Nature. 1999; 398:708. 
25. Koster MI, Roop DR. The role of p63 in development and differentiation of the epidermis: Tanioku Kihei memorial lecture. J Dermatol Sci. 2004;34:3-9.

26. Moore L, Lu X, Ghebranious N, Tyner S, Donehower LA. Aging-associated truncated form of p53 interacts with wild-type p53 and alters p53 stability, localization, and activity. Mech Ageing Dev. 2007;128:717-30.

27. Armata HL, Garlick DS, Sluss HK. The Ataxia telangiectasia-mutated target site Ser18 is required for p53-mediated tumor suppression. Cancer Res. 2007;67:11696-703.

28. Keyes WM, Wu Y, Vogel H, Guo X, Lowe SW, Mills AA. p63 deficiency activates a program of cellular senescence and leads to accelerated aging. Genes Dev. 2005;19:1986-99.

29. Rufini A, Tucci P, Celardo I, Melino G. Senescence and aging: the critical roles of p53. Oncogene. 2013:32:5129-43.

30. Yan BC, Jiang D, Wang J, et al. Both decreased Akt expression and mTOR phosphorylation are related to decreased neuronal differentiation in the hippocampal alveus of aged mice. Aging Clin Exp Res. 2018;30:737-43.

31. Choi HS, Ahn JH, Park JH, Won MH, Lee CH. Age-dependent changes in the protein expression levels of Redd1 and mTOR in the gerbil hippocampus during normal aging. Mol Med Rep. 2016;13:2409-14.

32. Hayakawa N, Yokoyama H, Kato H, Araki T. Age-related alterations of oxidative stress markers in the mouse hippocampal CA1 sector. Exp Mol Pathol. 2008:85:135-40.

33. Ahn JH, Chen BH, Shin BN, et al. Comparison of catalase immunoreactivity in the hippocampus between young, adult and aged mice and rats. Mol Med Rep. 2016;14:851-6.

\section{Publisher's Note}

Springer Nature remains neutral with regard to jurisdictional claims in published maps and institutional affiliations.

Ready to submit your research? Choose BMC and benefit from:

- fast, convenient online submission

- thorough peer review by experienced researchers in your field

- rapid publication on acceptance

- support for research data, including large and complex data types

- gold Open Access which fosters wider collaboration and increased citations

- maximum visibility for your research: over $100 \mathrm{M}$ website views per year

At $\mathrm{BMC}$, research is always in progress.

Learn more biomedcentral.com/submissions 